Journal of Applied Pharmaceutical Science Vol. 6 (02), pp. 081-086, February, 2016

Available online at http://www.japsonline.com

DOI: $10.7324 / J A P S .2016 .60211$

ISSN 2231-3354 (cc)) BY-NC-SA

\title{
Hepcidin TH1-5 Induces Apoptosis and Activate Caspase-9 in MCF-7 Cells
}

\author{
Mohammed Al-kassim Hassan ${ }^{\mathrm{a}, \mathrm{c}}$, Wan-Atirah Azemin ${ }^{\mathrm{b}}$, Saravanan Dharmaraj ${ }^{\mathrm{a}}$, Khamsah Suryati Mohd ${ }^{\mathrm{b}, \mathrm{d}^{*}}$ \\ ${ }^{a}$ Faculty of Medicine, Universiti Sultan Zainal Abidin, Medical Campus, Jalan Sultan Mahmud, 20400 Kuala Terengganu, Malaysia. ${ }^{b}$ Faculty of \\ Bioresources\& Food Industry, Universiti Sultan Zainal Abidin, Tembila Campus, 22200 Besut, Terengganu, Malaysia. ${ }^{c}$ Faculty of Pharmaceutical Sciences, \\ Bayero University, Kano. ${ }^{\mathrm{d}}$ Agriculture Production and Food Innovation Research Institute (AGROPOLIS), Universiti Sultan Zainal Abidin, Tembila \\ Campus, Besut, Terengganu, Malaysia.
}

\begin{tabular}{|c|c|}
\hline ARTICLE INFO & ABSTRACT \\
\hline Article history: & Breast cancer is the most commonly diagnosed and leading cause of cancer deaths among women globally. In \\
\hline Received on: 03/11/2015 & continuation of our investigation into the cytotoxicity of the antimicrobial peptide, Hepcidin TH1-5 on human \\
\hline Revised on: 04/12/2015 & breast adenocarcinoma cell line (MCF-7), we further affirm the apoptosis-inducing effect of the cysteine-rich \\
\hline Accepted on: 20/12/2015 & peptide in the present study. Annexin V-fluorescein isothiocyanate and propidium iodide (annexin V-FITC/PI) \\
\hline Available online: $27 / 02 / 2016$ & apoptosis assay was performed after treatment of the cells. In the determination of caspase activity and pathway \\
\hline Key words: & $\begin{array}{l}\text { of apoptosis, luminescent assay was also performed where caspase-3//, caspase- } 8 \text { and caspase-9 were evaluated. } \\
\text { Results of annexin V-FITC/PI staining showed proportion of early apoptotic cell were } 73.67 \pm 4.93 \%, 61.00 \pm\end{array}$ \\
\hline $\begin{array}{l}\text { Hepcidin TH1-5, apoptosis, } \\
\text { caspase, intrinsic, MCF-7. }\end{array}$ & $\begin{array}{l}5.57 \% \text { and } 44.33 \pm 2.52 \% \text { at } 24,48 \text { and } 72 \text { hours respectively, while late apoptotic cell were } 6.33 \pm 1.53 \%, 23 \pm \\
3.56 \% \text { and } 34 \pm 3.51 \% \text { within the same time interval. Based on the data from the luminescence test, Hepcidin } \\
\text { TH1 }-5 \text { activated caspases- }-3 / 7 \text { and }-9 \text { which suggests that the apoptosis induced was due to the peptide treatment. } \\
\text { Hepcidin TH1-5 induced apoptosis in MCF- } 7 \text { via the activation of caspase- } 9 \text { of the intrinsic pathway. These } \\
\text { results support our previous findings of the cytotoxicity of Hepcidin TH1-5 and indicate that the peptide may be a } \\
\text { potential agent for breast cancer therapy. }\end{array}$ \\
\hline
\end{tabular}

\section{INTRODUCTION}

Breast cancer is the most commonly diagnosed cancer and leading cause of cancer deaths among women globally. According to World Health Organization, 1.7 million new cases were diagnosed in the year 2012 with over half a million deaths recorded (WHO, 2014). In Malaysia, it accounts for $18.1 \%$ of all cancer cases with $32.1 \%$ of this affecting the female population, while the age-standardized rate stood at 29.1 per 100,000 population(Omar and Tamin, 2011). The upsurge of breast cancer in the developing world may be attributed to increasing life expectancy, increased urbanization and adoption of western lifestyle (WHO). Chemotherapy is the mainstay and one of the principle approaches to breast cancer therapy. The use of cytotoxic chemotherapy in the early and advanced stages of breast cancer has yielded significant improvement in curbing the

\footnotetext{
* Corresponding Author

Khamsah Suryati Mohd, Faculty of Bioresources and Food Industry, Universiti Sultan Zainal Abidin, Besut, Terengganu, Malaysia. Agriculture Production and Food Innovation Research Institute (AGROPOLIS), Universiti Sultan Zainal Abidin, Besut,

Terengganu, Malaysia.Email: khamsahsuryati@unisza.edu.my
}

disease in the last decade(Hassanet al., 2010). However, lack of selectivity, severe systemic toxicity and development of resistance to mention a few have limited the success of the conventional chemotherapeutic agents in curtailing the disease. These drawbacks underscore the need to search for alternative agents or therapeutic combinations that could provide better therapeutic outcome and improve the quality of life of breast cancer sufferers. Antimicrobial peptides (AMPs) are ancient molecules isolated from virtually all organisms including micro-organisms, plants, insects, reptiles, amphibians, fishes, birds and mammals including humans.

They are mostly cationic and amphipathic in nature; however, they can exist at variance to each other in their properties including size, charge, sequence and structural chemistry. They possess broad spectrum antimicrobial activities against Grampositive and Gram-negative bacteria, fungi and viruses (Zasloff, 2002). AMPs have pulled significant research interest due to their biochemical diversity, broad antimicrobial spectrum and wider biological applications including antitumor effects (Zasloff, 2002). The wide range of bioactivities of AMPs, particularly cytotoxicity effect, has placed them as potential agents for chemotherapy. 
They have been reported for their anticancer properties (Al-Benna et al., 2011; Dennisonet al., 2006; Mader \& Hoskin, 2006; Papo \& Shai, 2005), and these compounds have been recognized as potential alternative chemotherapeutic agents that may overcome some of the limitations of oncolytic drugs (Papo and Shai, 2005; Steinstraesser et al., 2009). Some of the merits of the AMPs include selective toxicity for cancer cells, rapid cell kill, and ability to evade multidrug resistance mechanisms. Others include low toxicity profile and additive effect in combination therapy (Hancock and Patrzykat, 2002; Papo and Shai, 2005; Hoskin and Ramamoorthy, 2008).

Fish-derived AMPs represent an excellent source from which bioactive peptides of pharmaceutical and therapeutic interests have been explored lately. Several AMPs have been identified from fishes including pleurocidin, piscidin, pardaxin, chrysophsins and Hepcidins (Rajanbabu and Chen 2011). Of the three isoforms of Hepcidins obtained from tilapia fish Oreochromis mossambicus, only TH1-5 and TH2-3 isoforms have displayed cytotoxicity. Human cervical carcinoma (HeLa) and human hepatocellular carcinoma (HepG2) cell lines were susceptible to TH1-5 while human fibrosarcoma cell line (HT1080) was inhibited by both peptides (Chang et al., 2011; Chen et al., 2009).

In the present study, we investigate the cytotoxicity of synthetic Hepcidin TH1-5 against human breast adenocarcinoma cell line MCF-7 as well as its mode of cell death.

\section{MATERIALS AND METHODS}

\section{The peptide}

Synthetic form of Hepcidin TH1-5 (GIKCRFCCGCCTPGICGVCCRF) was purchased from Mimotopes The Peptide Company (Victoria, Australia). The peptide was reconstituted in phosphate-buffered saline (PBS, pH 7.4) before use. Methotrexate was obtained from Sigma-Aldrich, USA.

\section{Cell lines and culture}

Human breast adenocarcinoma (MCF-7) and normal mouse embryonic fibroblast (NIH/3T3) cell lines were purchased from American Type Culture Collection (ATCC, Manassas, VA, USA). Both cell lines were cultured in RPMI-1640 medium supplemented with $10 \% \mathrm{v} / \mathrm{v}$ heat-inactivated fetal bovine serum (FBS), $100 \mathrm{mg} / \mathrm{L}$ streptomycin and 100, $000 \mathrm{IU}$ penicillin. Cells were passaged every 3-4 days based on the confluency and maintained at $37^{\circ} \mathrm{C}$ in a humidified $5 \% \mathrm{CO}_{2}$ and $95 \%$ oxygen incubator.

\section{Reagents and kits}

RPMI-1640 medium, fetal bovine serum, were purchased from Gibco (USA); Penicillin-Streptomycin mixture from Nacalaitesque, Kyoto Japan; 3-(4,5-dimethylthiazol-2-yl)-2,5diphenyltetrazolium bromide (MTT) dye was purchased from Sigma-Aldrich (St. Louis, USA); Annexin V-FITC and propidium iodide were obtained from BD Biosciences (USA); while caspase$3 / 7$, caspase- 8 and caspase- 9 were purchased from Promega (USA).

\section{Cell viability assay}

In order to evaluate effect of Hepcidin TH1-5 on cell growth, cells at a density $1 \times 10^{5} /$ well were plated in 96 -well plate for 24 hours. Cells were then treated with serial concentrations of the peptide and incubated for 72 hours. MTT assay was carried out as described by Xu et al (2013).

\section{Annexin V-FITC/PI apoptosis assay}

Apoptosis of MCF-7 cells was further demonstrated by double staining with annexin $\mathrm{V}$ conjugated with fluorescein isothiocyanate (FITC) and propidium iodide in line with the kits protocols (BD Biosciences, USA). Cells were seeded in 6-well plate $\left(1 \times 10^{5}\right.$ cells/well) and incubated overnight to attain the desired confluency.

Treatment with Hepcidin TH1-5 was followed by incubation for 24, 48 and 72 hours in different plates. Cells were then harvested, centrifuged and washed with cold PBS. Cell pellet was treated with $1 \mathrm{x}$ binding buffer, and suspended in $5 \mu \mathrm{L}$ of annexin-V/FITC and $5 \mu \mathrm{L}$ propidium iodide $(2 \mu \mathrm{g} / \mathrm{mL})$. The cell suspension was incubated in the dark for 15 minutes on ice. Ten microliters of the stained cell suspension was pipetted onto a microscopic slide, covered with a coverslip and observed under a fluorescence microscope (Nikon Eclipse, Japan). Cells were counted and categorized accordingly in a random population of 200 .

\section{Caspase luminescence assay}

Caspase activities were tested in MCF-7 using CaspaseGlo $^{\circledR}$ 3/7, Caspase-Glo ${ }^{\circledR} 8$ and Caspase-Glo ${ }^{\circledR} 9$ Assay Kits (Promega, USA) following the manufacturer's protocols. MCF-7 cells at a density of $2 \times 10^{5}$ were treated with Hepcidin TH1-5 for 12, 24 and 48 hours (methotrexate was used as positive control). Cells were harvested, counted and plated in 96-well optiplate with a transparent bottom (Perkin Elmer, USA). A volume of $25 \mu \mathrm{L}$ of freshly prepared mixture of each caspase substrate and its buffer were added to the wells containing the cells in equal amount in the dark and incubated at $37^{\circ} \mathrm{C} 5 \% \mathrm{CO}_{2}$ for 4 hours. Luminescence was read using microplate reader (Tecan Infinite M200, Switzerland).

The intensity of luminescence signals measured in relative light units (RLU) is directly proportional to the caspase activity. The experiment was carried out in triplicates.

\section{Statistical analysis}

Statistical analyses were carried out using Graph Pad Prism version 5.01 for Windows, (GraphPad Software, San Diego California, USA).Data were analyzed using one-way analysis of variance (ANOVA) followed by Tukey's post-test and data were considered statistically significant at $\mathrm{P}<0.05$. 


\section{RESULTS}

\section{Effect of Hepcidin TH1-5 on MCF-7 viability}

Hepcidin TH1-5 was examined for its cytotoxic effect on MCF-7 at various doses, and the result is shown in Fig. 1 below. For MCF-7 treated with the peptide, percentages of cell viability at the various concentrations are indicated in Fig 1a. This effect was correspondingly dependent on the concentration of the peptide where cell viability decreases with increasing peptide concentration. A similar pattern was also seen in the normal mouse fibroblast (Fig. 1b). Ahalf maximal inhibitory concentration $\left(\mathrm{IC}_{50}\right)$ of $20 \mu \mathrm{g} / \mathrm{mL}$ was obtained for Hepcidin TH1-5 against MCF-7 as reported in our previous work (Hassan et al., 2015).
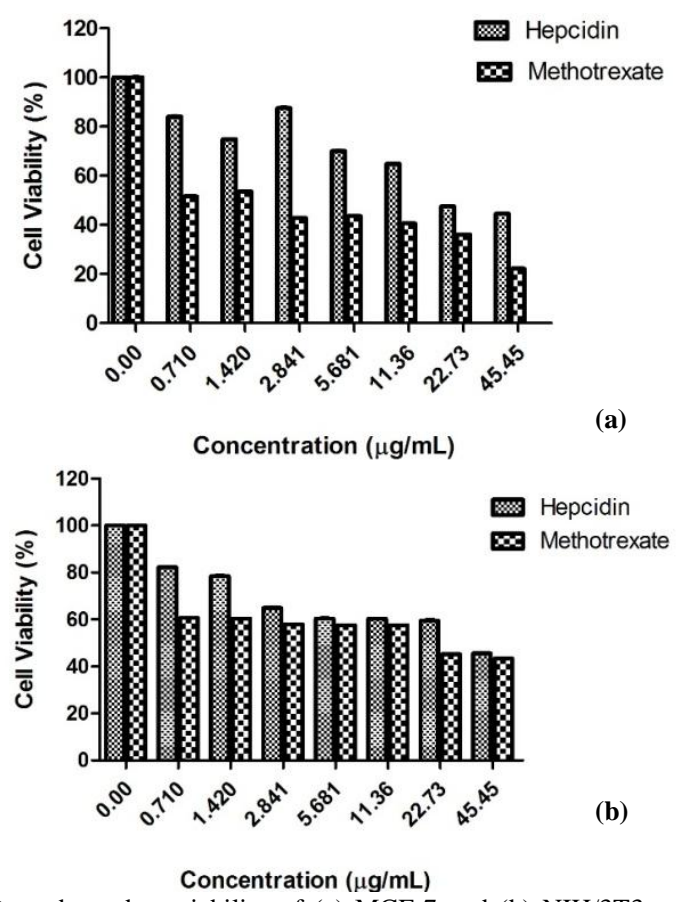

Fig. 1: Dose-dependent viability of (a) MCF-7 and (b) NIH/3T3 cells. Cells were treated with serial concentrations of Hepcidin TH1-5 and methotrexate and incubated for 72 hours before carrying out MTT assay.

\section{Annexin V-FITC/PI apoptosis assay}

To further support our previous finding on the apoptotic induction by Hepcidin TH1-5, we further subject MCF-7 to annexin V-FITC/PI apoptotic detection. Propidium iodide was employed as a counterstain to distinguish necrotic cells from apoptotic ones. Indeed, Hepcidin TH1-5 treatment caused apoptotic induction of $\mathrm{MCF}-7$ at the $\mathrm{IC}_{50}$ concentration. At 24 hours (Fig. 3a), approximately $73.67 \pm 4.93 \%$ of cells treated by Hepcidin TH1-5 were in the early apoptotic phase, $4.33 \pm 2.08 \%$ were late apoptotic, $1.67 \pm 1.02 \%$ were necrotic while the remaining were normal viable cells. At 48 hours (Fig. 3b), early apoptotic, late apoptotic and necrotic cells account for $61 \pm 5.57 \%$, $23 \pm 3.56 \%$ and $3.67 \pm 2.00 \%$ respectively. This shows a little decrease in early apoptosis but overall the apoptotic death effect was more. Similarly, this decline was also consistent as incubation time increased to 72 hours. Approximately 44.33 $\pm 2.52 \%, 34.33 \pm$ $3.51 \%, 9.67 \pm 1.53 \%$ account for early apoptosis, late apoptosis and necrotic cell correspondingly $(\mathrm{P}<0.05$ relative to untreated cells at the same time); while the deficit account for viable cells (Fig. 3c). Overall, this indicates that the apoptosis effect induced is influenced by time. For the control (untreated) cells, about 93 \pm $1.00 \%, 80.33 \pm 3.21 \%$ and $74.67 \pm 8.14 \%$ remained viable at 24,48 and 72 hours respectively, while early and late apoptotic cells account for the remaining percent. Statistical significant differences was observed $(\mathrm{P}<0.05)$ between the stages of cell death (apoptosis and necrotic) and untreated cells as shown in Fig. $3(\mathrm{a}, \mathrm{b}, \mathrm{c})$.
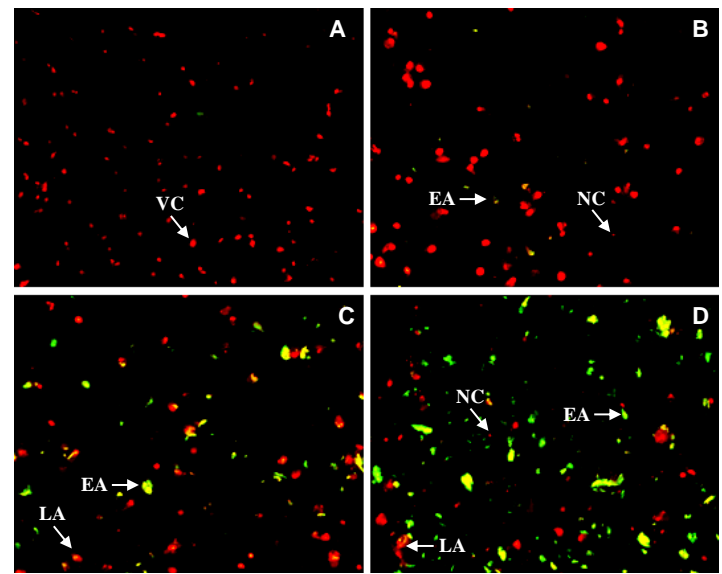

Fig. 2: Annexin V-FITC/PI apoptosis detection. MCF-7 cells were stained with annexin V-FITC/PI after treatment with Hepcidin TH1-5 and then examined under a florescence microscope (a) control (b) $24 \mathrm{~h}$ (c) $48 \mathrm{~h}$ (d) $72 \mathrm{~h}$.. The result showed apoptosis of MCF-7 cells increased $72 \mathrm{~h}$ after peptide treatment as compared to the control group. Untreated cells were annexin V-FITC/PI negative, apoptotic cells were annexin V-FITC positive, PI negative while necrotic or late apoptosis cells were annexin V-FITC/PI positive (Magnification 200x).

\section{Caspase assay}

Caspase $3 / 7$, caspase- 8 and caspase- 9 activities were each measured in MCF-7 at 12, 24 and 48 hours. Result from the assay showed Hepcidin TH1-5 demonstrated cytotoxicity against human breast cancer cell line. As shown from the graphs (Figs. 4a, $4 \mathrm{~b}$ and $4 \mathrm{c}$ ), the peptide activates caspases-3/7, -8 and -9 but to varying degrees. The caspases' activities following MCF-7 treatment with the peptide were measured by the intensity of the luminescence (RLU). The peptide activated caspase-3/7 and caspase- 9 as evidenced by the elevated enzymatic activities of the caspases thereby inducing apoptosis in human breast cancer cell line. At 12 h (Fig. 4a), caspases $-3 / 7$ and -9 were activated by Hepcidin TH1-5 unlike caspase- 8 of which the effect was somewhat negligible and insignificant. This intensity of activity was further increased to about 40000 RLU and statistical significance from the control (untreated) cells was observed in both caspases $-3 / 7$ and -9 . At $48 \mathrm{~h}$, caspase activation was very prominent where activation of caspases $-3 / 7$ and -9 were at equal intensity as shown in Fig. 4b. On the other hand, activation of caspase-9 was highest for Hepcidin TH1-5 with value of about 120 000 RLU, and there was significant statistical difference compared to the control group (Fig. 4c). This effect shows that activation of caspases $-3 / 7$ and -9 by Hepcidin TH1-5 was time-dependent. 

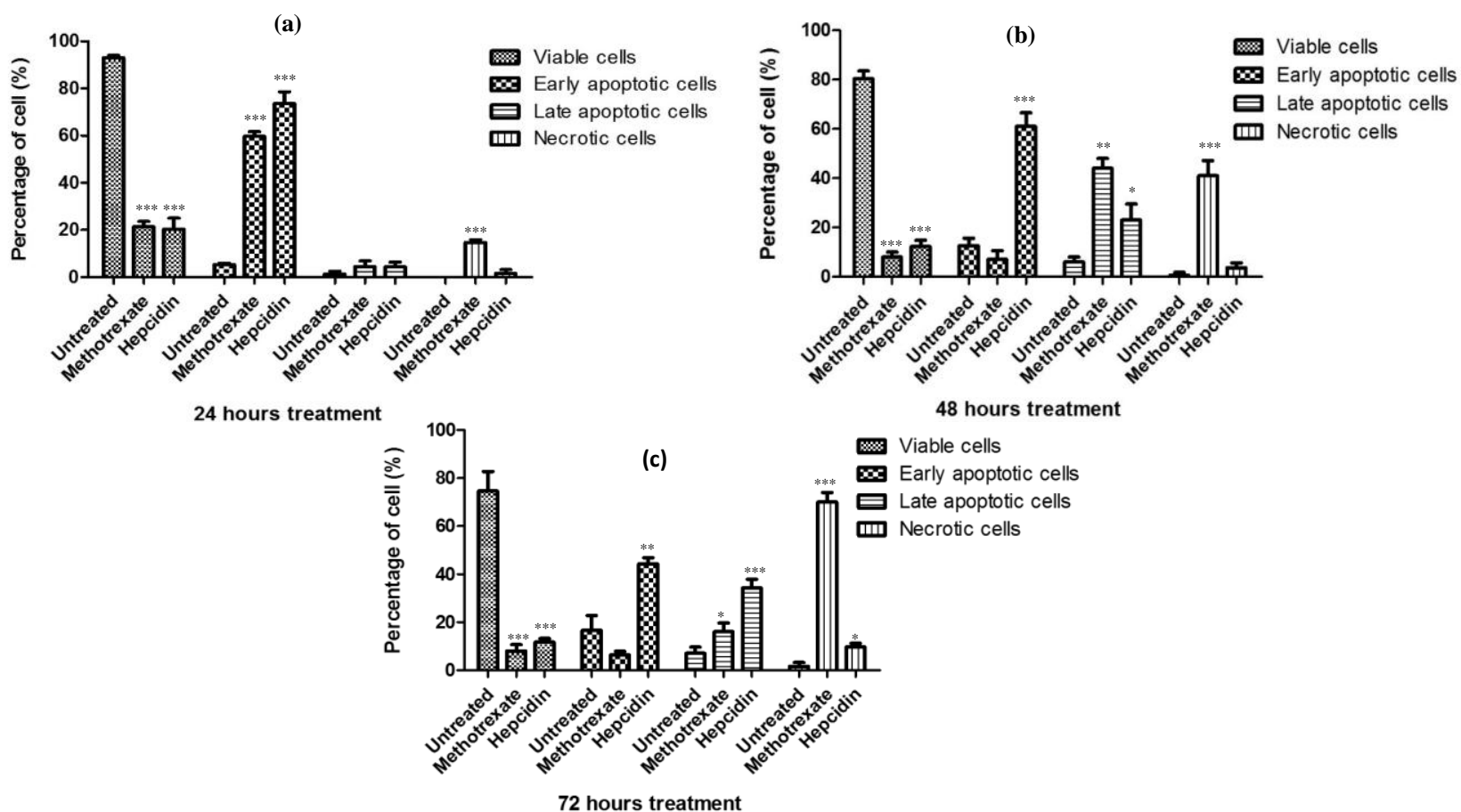

Fig. 3: Annexin V-FITC/PI apoptosis assay. Cells were treated for (a) 24 , (b) 48 and (c) 72 hours before subjected to staining. Data represent mean \pm SD for three replicate experiments. Data were analyzed by one-way ANOVA and statistical significance in relation to the control (untreated) was observed at $* \mathrm{p}<0.05$, $* * \mathrm{p}<0.01, * * * \mathrm{p}<0.001$
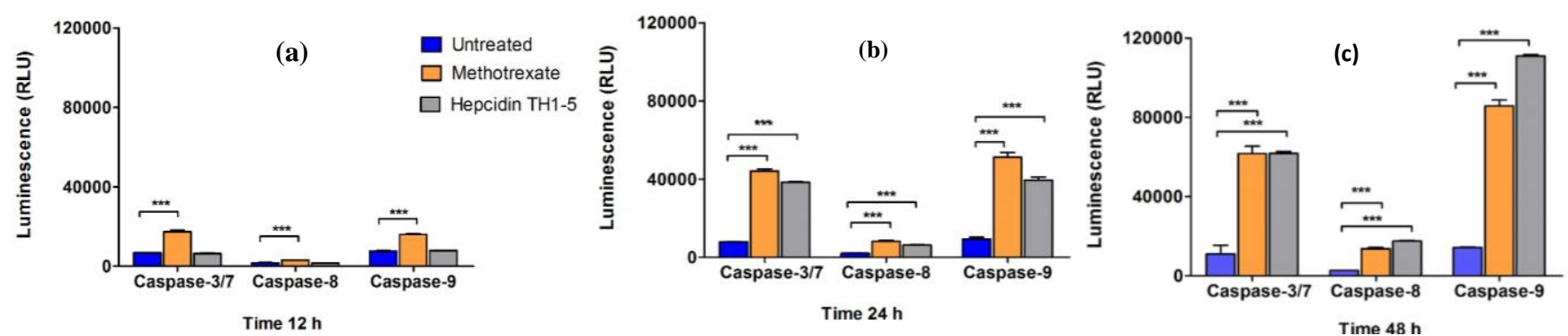

Fig. 4: Caspase activity on MCF-7 cells. Cells were treated and incubated for (a) 12 hours (b) 24 hours (c) 48 hours before exposure to various caspase substrates and incubated for $4 \mathrm{~h}$. Luminescence was detected using the microplate reader. Results are expressed as mean \pm SD of three replicate experiments. Data were analyzed by one-way ANOVA and statistical significance was observed $* * * \mathrm{P}<0.001$

\section{DISCUSSION}

In our previous findings, the $\mathrm{IC}_{50}$ of Hepcidin $\mathrm{TH} 1-5$ against MCF-7 from MTT assay after $72 \mathrm{~h}$ incubation was 20 $\mu \mathrm{g} / \mathrm{mL}$. This concentration was employed for further investigations into the cytotoxic effect of the peptide. Apoptosis normally occurs during development and aging and as a homeostatic mechanism to maintain cell populations in tissues. It also occurs as a defense mechanism such as in immune reactions or when cells are damaged by disease or noxious agents (Norbury and Hickson, 2001). Evasion of apoptosis or defects in its pathways play a crucial role in carcinogenesis and tumor progression and most cancer treatment strategies target this process and its pathways in achieving remission (Wong, 2011). Failure of apoptosis induction in cancer chemotherapy can also lead to drug resistance. Therefore, agents that can induce apoptotic cell death in cancer cells are potential anticancer agents (Park et al. 2011).In the present study, annexinV-FITC/PI double staining indicated that majority of the MCF-7 cells underwent apoptotic cell death mode after Hepcidin TH1-5 treatment. Cells that have their membrane integrity disrupted appear red to PI staining in their nucleus and a green stain (FITC) around cell surface( $\mathrm{Su}$ et al., 2011). In comparison with the untreated (control) group (Fig.2A), there was increased apoptotic cells observed after staining with the conjugated dyes followed by flourescence microscopy evaluation. As the time of exposure to the cytotoxic agent increases, cell death becomes more prominent whereby cells release their fragments or apoptotic bodies which are engulfed by macrophages, and the effect is more pronounced especially at 72 hours. Although, both apoptotic and necrotic cells co-exist in most of the micrographs, the apoptotic cells predominate. Additionally, the necrotic cells do not entirely lose their membrane integrity as shown in Fig.2. Significant differences were demonstrated in the apoptotic events due to Hepcidin TH1-5 treatment as compared to the control cells across the three different times i.e. 24, 48 and 72 hours. Previous studies indicated that Hepcidin TH1-5 caused apoptosis. Hepcidin 
1-5 caused cell cycle arrest at the $G_{0} / G_{1}$ phase and triggered apoptosis as displayed by the externalization of annexin $\mathrm{V}$-targeted phosphatidylserine in HeLa cells (Chang et al., 2011). The peptide was also reported to induce apoptosisin HepG2 cells in which $61.2 \%$ of the cells were in the early apoptosis after 24 hours of treatment but drifted to late apoptosis $(79.7 \%)$ with prolonged incubation at 72 hours. Hepcidin TH1-5 also caused cell cycle arrest in HepG2 at the G2/M phase (Mohd et al., 2015).

Intrinsic and extrinsic pathways are the two common pathways of apoptosis. These two initiation pathways ultimately lead to common pathway or the execution pathway of apoptosis (Wong 2011). Caspases are signaling molecules that mediate cell death and play a fundamental role in apoptosis. Their activation also is an indicator of cellular damage in diseases (Lavrik et al., 2005)including cancer. They are key effector molecules in apoptosis, and potential targets for pharmacological modulation of cell death (Lavrik et al., 2005). The intrinsic pathway characterized by increased mitochondrial permeability is initiated within the cell and regulated by the Bcl-2 family of proteins which consists of pro- and anti-apoptotic proteins(Sankari et al., 2012). Conversely, the extrinsic pathway is induced following activation of the death receptors belonging to the tumor necrosis factor receptor family, such as TNFR and Fas (Duprez et al., 2009). For the untreated MCF-7 cells, caspase-3/7 and caspase- 9 activities increased with increased incubation time which indicates minimal apoptosis of the healthy cells as an innate occurrence of proliferating cells. Activation of caspase- 3 has been regarded as the hallmark of apoptosis in that it is the executioner caspase and one of the most critical enzymes of apoptosis. It played a central role in facilitating nuclear apoptosis including membrane blebbing, chromatin condensation and DNA fragmentation. However, its activity is tissue, cell type and death stimulus-specific (Porter and Jänicke, 1999). Hepcidin TH1-5 also activated caspase-3/7 at 12, 24 and $48 \mathrm{~h}$ in a time-dependent manner.

This effect was also observed in the control drug (methotrexate) in which at $48 \mathrm{~h}$ its effect tied with that of the test peptide. On the other hand, caspase- 9 which is an initiator phase, was also activated by both agents. Although, with increase in time (48h), Hepcidin TH1-5 displayed increased activity which suggests that the peptide trigger the activation slowly but with sustained effect. At the execution phase, within the same time, it showed a remarkable accomplishment. A previous study by Chang et al(2011) reported Hepcidin 1-5 treatment against HeLa led to down-regulated gene expression of caspase-7 the protease involved in apoptosis and inflammation (Lamkanfi and Kanneganti, 2011), and this is suggestive that the peptide may have induced both apoptosis and inflammation. Caspase- 8 played its key role in extrinsic apoptosis which is not duly expressed in the outcome of this investigation. Both caspases -8 and -9 constitute the initiator caspases which exist in their inactive procaspase monomers and are activated by dimerization (McIlwainet al., 2013). Caspase-9 is the initiator caspase in charge of the intrinsic pathway of apoptosis (Shiozakiet al., 2002). Caspases induction in MCF-7 cells occasioned by Hepcidin TH1-5 treatment follows a time-dependent course as shown by the luminescence assay plot. This conforms to the outcomes in the mode of cell death experiment (annexin V-FITC/PI) where cell death by apoptosis peaks between 48 and 72 hours. Although it has been established that the use of apoptosis-inducing agents have been employed in cancer chemotherapy, most of these compounds are subject to the same limitations of delivery and specificity just as in conventional chemotherapeutics (McIlwain et al., 2013). The unique properties of AMPs, i.e., drug delivery vectors, amphipathicity and discriminant selectivity for cancer cells, may have address these challenges and thus presenting this class of compounds as potential novel candidates for the treatment of cancer. Based on the observations from the mode of cell death and data emanating from the caspase luminescence assay, it is likely to be argued that synthetic Hepcidin TH1-5 induced apoptosis. The peptide also activated caspase- 9 of the intrinsic pathway as well as caspase- 3 which plays the crucial role in apoptosis.

\section{CONCLUSION}

Results from the study have shown that synthetic Hepcidin TH1-5 demonstrated cytotoxicity and apoptosis induction phenomenon against human breast cancer cell line MCF7. It induced these effects by inhibiting cell proliferation, and induction of apoptosis via the activation of caspase-3/7 and caspase-9. Hepcidin TH1-5 appeared a good candidate for development as a potential agent for breast cancer therapy. However, further investigations are requisite to buttress these findings and further explore the scope of its cytotoxic potentials.

\section{CONFLICT OF INTEREST}

The authors declare no conflict of interest.

\section{ACKNOWLEDGEMENT}

This study was financially supported by a grant from the Ministry of Higher Education Malaysia (FRGS RR040).

\section{REFERENCES}

Al-Benna S, Shai Y, Jacobsen F, Steinstraesser L. Oncolytic activities of host defense peptides. Int J Mol Sci, 2011;12(11):8027-51.

Chang W-T, Pan C-Y, Rajanbabu V, Cheng C-W, Chen J-Y. Tilapia (Oreochromis mossambicus) antimicrobial peptide, Hepcidin 1-5, shows antitumor activity in cancer cells. Peptides, 201;32(2):342-52.

Chen J-Y, Lin W-J, Lin T-L. A fish antimicrobial peptide, tilapia Hepcidin $\mathrm{TH} 2-3$, shows potent antitumor activity against human fibrosarcoma cells. Peptides, 2009;30(9):1636-42.

Dennison SR, Whittaker M, Harris F, Phoenix DA. Anticancer alpha-helical peptides and structure/function relationships underpinning their interactions with tumour cell membranes. Curr Protein Pept Sci, 2006;7(6):487-99.

Duprez L, Wirawan E, Vanden Berghe T, Vandenabeele P. Major cell death pathways at a glance. Microbes Infect, 2009; 11(13): $1050-62$.

Hancock REW, Patrzykat A. Clinical development of cationic antimicrobial peptides: from natural to novel antibiotics. Curr Drug Targets Infect Disord, 2002;2(1):79-83. 
Hassan MA, Mohd KS, Azemin W-A, Dharmaraj S. Cytotoxic effect of Hepcidin (TH1-5) on human breast cancer cellline MCF-7. Jurnal Teknologi, 2015; 77(3):73-79.

Hassan MSU, Ansari J, Spooner D, Hussain SA. Chemotherapy for breast cancer (Review). Oncol Rep, 2010;24(5):1121-31.

Hoskin DW, Ramamoorthy A. Studies on anticancer activities of antimicrobial peptides. Biochim Biophys Acta, 2008; 1778(2):357-75.

Lamkanfi M, Kanneganti T-D. Caspase-7: a protease involved in apoptosis and inflammation. Int J Biocemistry Cell Biol, 2010; 42(1):21-24.

Lavrik IN, Golks A, Krammer PH. Caspases: pharmacological manipulation of cell death. J Clin Invest, 2005;115(10):2665-72.

Mader JS, Hoskin DW. Cationic antimicrobial peptides as novel cytotoxic agents for cancer treatment. Expert Opin Investig Drugs, 2006;15(8):933-46.

Mcllwain DR, Berger T, Mak TW. Caspase functions in cell death and disease. Cold Spring Harb Perspect Biol, 2013;5(4):a008656.

Mohd KS, Azemin WA, Ali AM. Induction of apoptosis and G2/M phase cell cycle arrest by antimicrobial peptide HepTH1-5. In: International Conference on Natural Product 2015, 24-25 March 2015, Johor Bharu.

Norbury CJ, Hickson ID. Cellular responses to DNA damage. Annu Rev Pharmacol Toxicol, 2001;4(1):367-401.

Omar ZA, Tamin NSI. National Cancer Registry Report 2007.Malaysia Cancer Statistics-Data and Figure, Kuala Lumpur: National Cancer Registry, Ministry of Health Malaysia, 2011, 89.

Papo N, Shai Y. Host defense peptides as new weapons in cancer treatment. Cell Mol Life Sci, 2005;62(7-8):784-90.

Park MH, Choi MS, Kwak DH, Oh K-W, Yoon DY, Han SB, et al. Anti-cancer effect of bee venom in prostate cancer cells through activation of caspase pathway via inactivation of NF- $\kappa$ B. Prostate, 2011;71(8):801-12.

Porter AG, Jänicke RU. Emerging roles of caspase-3 in apoptosis. Cell Death Differ, 1999;6(2):99-104.

Rajanbabu V, Chen J-Y. Applications of antimicrobial peptides from fish and perspectives for the future. Peptides, 2011;32(2):415-20.
Sankari SL, Masthan KMK, Babu NA, Bhattacharjee T, Elumalai M. Apoptosis in cancer - an update. Asian Pacific J Cancer Prev, 2012;13(10):4873-8.

Shiozaki EN, Chai J, Shi Y. Oligomerization and activation of caspase-9, induced by Apaf-1 CARD. Proc Natl Acad Sci USA, 2002;99(7):4197-202.

Steinstraesser L, Kraneburg UM, Hirsch T, Kesting M, Jacobsen F, Al-benna S. Host defense peptides as effector molecules of the innate immune response : asledgehammer for drug resistance? Int $\mathrm{J}$ Mol Sci, 2009; 10(9):3951-70.

$\mathrm{Su} \mathrm{X}, \mathrm{Xu} \mathrm{C}$, Li Y, Gao X, Lou Y. Antitumor activity of polysaccharides and saponin extracted from sea cucumber. J Clin Cell Immunol, 2011; 02(105).

WHO. GLOBOCAN 2012: Estimated cancer incidence, mortality and prevalence worldwide in 2012. Lyon, Fr Int Agency Res Cancer, 2014

WHO. Breast cancer awareness in October. Avaialble at www.who.int/cancer/events/breast_cancer_month/en/ [Accessed 15 November 2015].

Wong RSY. Apoptosis in cancer: from pathogenesis to treatment. J Exp Clin Cancer Res, 2011;30(1):87.

$\mathrm{Xu} \mathrm{H}$, Chen CX, Hu J, Zhou P, Zeng P, Cao CH, et al. Dual modes of antitumor action of an amphiphilic peptide $\mathrm{A}_{(9)} \mathrm{K}$. Biomaterials, 2013;34(11):2731-7.

Zasloff M. Antimicrobial peptides of multicellular organisms. Nature, 2002;415(6870):389-95.

\section{How to cite this article:}

Hassan MA, Azemin W, Dharmaraj S, Mohd KS. Hepcidin Th1-5 Induces Apoptosis and Activate Caspase-9 in Mcf-7 Cells. J App Pharm Sci, 2016; 6 (02): 081-086. 